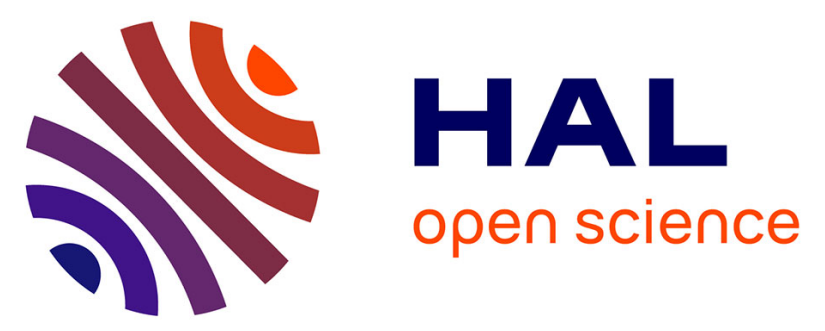

\title{
Advancing Circular Economy: Research Roadmap for Circular Integrated Production Systems
}

Magdalena Paul, Simon Thevenin, Julia Schulz, Nadjib Brahimi, Hichem

Haddou Benderbal, Alexandre Dolgui

\section{- To cite this version:}

Magdalena Paul, Simon Thevenin, Julia Schulz, Nadjib Brahimi, Hichem Haddou Benderbal, et al.. Advancing Circular Economy: Research Roadmap for Circular Integrated Production Systems. 22nd Working Conference on Virtual Enterprises (PRO-VE 2021), Nov 2021, Saint-Etienne, France. pp.789796, 10.1007/978-3-030-85969-5_75 . emse-03350984

\section{HAL Id: emse-03350984 \\ https://hal-emse.ccsd.cnrs.fr/emse-03350984}

Submitted on 25 Nov 2021

HAL is a multi-disciplinary open access archive for the deposit and dissemination of scientific research documents, whether they are published or not. The documents may come from teaching and research institutions in France or abroad, or from public or private research centers.
L'archive ouverte pluridisciplinaire $\mathbf{H A L}$, est destinée au dépôt et à la diffusion de documents scientifiques de niveau recherche, publiés ou non, émanant des établissements d'enseignement et de recherche français ou étrangers, des laboratoires publics ou privés. 
Paul M., Thevenin S., Schulz J., Brahimi N., Benderbal H.H., Dolgui A. (2021) Advancing Circular Economy: Research Roadmap for Circular Integrated Production Systems. In: Camarinha-Matos L.M., Boucher X., Afsarmanesh H. (eds) Smart and Sustainable Collaborative Networks 4.0. PRO-VE 2021. IFIP Advances in Information and Communication Technology, vol 629. Springer, Cham. https://doi.org/10.1007/978-3030-85969-5_75

\title{
Advancing Circular Economy: Research Roadmap for Circular Integrated Production Systems
}

\author{
Magdalena Paul ${ }^{1}$, Simon Thevenin ${ }^{2}$, Julia Schulz ${ }^{1}$, \\ Nadjib Brahimi ${ }^{2,3}$, Hichem Haddou Benderbal ${ }^{2}$, Alexandre Dolgui ${ }^{2}$ \\ ${ }^{1}$ Technical University of Munich, Institute for Machine Tools and Industrial Management, \\ 85748 Garching, Germany \\ \{magdalena.paul, julia schulz\}@iwb.tum.de \\ ${ }^{2}$ IMT Atlantique, LS2N-CNRS, Nantes, France \\ \{alexandre.dolgui, simon.thevenin, hichem.haddou-ben-derbal\}@imt-atlantique.fr \\ ${ }^{3}$ Rennes School of Business, Rennes, France \\ nadjib.brahimi@rennes-sb.com
}

\begin{abstract}
The coronavirus crisis had a critical impact on supply chains and production worldwide. In particular, closed borders often prevented companies from obtaining the components required for their production. Such disruptions are the results of globalization, with suppliers spreading all over the world. The circular economy is an opportunity to overcome this challenge since components from end-of-life items may substitute supplies from afar. However, many barriers exist in the implementation of circular processes, as manufacturers perceive it as a radical change to their procedures. Therefore, we propose not to use completely new lines for the circular economy, but to use already existing systems. This paper presents the definition of circular integrated production systems (CIPS) and suggests a research roadmap for such to investigate what challenges and potentials arise, and what future research will be needed.
\end{abstract}

Keywords: Disassembly, Remanufacturing, Sustainable Production, Integrated Production Lines, Circular Economy.

\section{Introduction}

When parts are not available, production is interrupted: the recent coronavirus crisis demonstrates the critical impact of supply chain disruptions, as many companies are unable to source the components required for their productions, often due to closed borders $[1,2]$. The circular economy can make a major contribution to address this challenge: Products return to factories at the end of their life cycle instead of ending up in a landfill. In this way, locally available resources are used and companies are less dependent on distant suppliers. In addition, increasing environmental awareness and scarcity of available resources are putting pressure on companies to manage 
available resources in the domestic market. A circular approach can change the company's perspective: Instead of seeing used products as a liability, they can now be a source of parts or materials.

The purpose of this paper is to give a research roadmap for a new production paradigm. So-called circular integrated production systems (CIPS) should help to enable circular economy for more companies. Therefore, this paper compiles the current and previous research results to derive existing research gaps on circular production systems with integrated lines. In addition, specific action areas are defined to describe a roadmap for further research on the outlined topic. After describing the path from conventional production systems to circular integrated production systems (Section 2), the manuscript includes a section that divides the aforementioned research roadmap into the design (Section 3.1) and operation (Section 3.2) of CIPS, leading to a summary overview (Section 3.3). Section 4 discusses the results and draws a conclusion.

\section{The Way from Conventional Production Systems to Circular Integrated Production Systems (CIPS)}

The conventional production triangle, which describes the conflict between time, cost, and quality, is gradually being superseded by the holistic approach of sustainable production. Sustainable production combines economic, ecological and social aspects of value-adding activities. Due to regulation and green consumerism, most manufacturing companies are now willing to adopt more sustainable practices such as circular economy. This trend will likely increase in the coming years, since laws and regulations will become stricter pushing the manufacturing industry even more into a sustainable direction. For instance, the European Commission recently adopted the "Right to Repair", obliging the manufacturing industry to provide long-lasting machines and spare parts and to repair electronic equipment. Nevertheless, only a few companies are remanufacturing end-of-life items. Despite the willingness of the industry, several barriers prevent the adoption of circular economy. The barriers can be economical (high costs to build the reverse system, costs to manage the reverse inventory, not realizing the value, etc.), operational (lack of know-how, lack of guideline, coordination issues, etc.), environmental (lack of laws and regulations regarding end-of-life items, lack of government policy to support a return flow, etc.), socio-cultural (acceptance of remanufactured parts from customers, etc.), technological (current information systems mostly do not support circularity, etc.) or strategic (lack of management commitment, lack of performance indicators, etc.) [3].

To mitigate these barriers, the authors suggest a new approach of integrating circular economy into conventional production systems:

Circular integrated production systems (CIPS) are defined as production systems that can perform both conventional linear processes and circular activities on the same systems. 
Disassembly or remanufacturing are examples for circular activities in manufacturing companies. Within CIPS, existing elements, such as assembly lines, transport network, planning and scheduling software, and operation management, of factories mostly remain as they are designed for linear production, and are only adapted to comply with circular flows while minimizing costs of reconfiguration and the environmental impact. CIPS will not only reduce waste and enhance ecological sustainability but will also be a profitable form of processing of used products into existing lines. Returning products e.g. through recycling or remanufacturing can satisfy the rising customer demand for sustainable products. The creation of CIPS opens up local sources of supply for components and can therefore mitigate the risks of production stoppages during global supply chain disruptions.

\section{Research Roadmap for CIPS}

Before CIPS can be implemented in companies, there are still questions to be answered and challenges to be overcome. On the one hand, qualitative research is required to analyze and describe the type of industry that can use the system and methodology to operate the resulting integrated lines. The conditions under which a company can benefit from an integrated circular production system with identical elements being used for linear and circular activities need to be analyzed. This analysis includes the characteristics of the products and those of the factory, along with the internal and external environment. On the other hand, quantitative research must be performed to provide methodologies and software solutions to help manufacturers design a production system integrating an end-of-life item recovery process into an existing production process. More precisely, manufacturers must possess tools for (1) process planning and (2) operating a factory with integrated lines. The integration of circular processes creates challenges for capacity planning since it uses the same resources as the initial production and for requirement planning; for example recovered parts can be used for the initial production. Furthermore, a major challenge in the operation management is to deal with the arising uncertainty regarding the amount, the quality and the condition of revised products or parts.

\subsection{Designing a Circular Integrated Production System}

Definition of the System Boundaries and External Influences. Research on sustainability in production systems and supply chain management has been subject of a lot of interest during the last two decades. This research has taken several forms including work related to green logistics [4], design of processes for the treatment of returns through remanufacturing and refurbishing [5] and energy and resource usage along the supply chain [6]. Moreover, recycling and reuse are fundamental processing steps for products and their components, which are incorporated in disassembly. Disassembly is considered an important aspect of end-of-life product treatment [7]. In this context, researchers have either considered that returns are processed in a dedicated plant or within the same assembly plants of new products. The latter are called hybrid systems and have been studied from various perspectives. A 
classification of these studies can be found in [8]. One of the views considers two completely separate lines, where the disassembly line provides the assembly line with remanufactured parts that can be considered to be as good as new [9].

Further research is required to identify the prerequisites, barriers and enablers for the integration and introduction of circular activities in linear production companies. Such work must systematize the initial situation, analyze the internal and external requirements for implementing CIPS, and define the scope and boundaries. Qualitative research must include the following aspects:

- Analysis of aspects related to industrial circular economy to derive industry sectors that are suitable for integrated production systems

- Analysis of aspects related to in-house logistics, depth of in-house manufacturing as well as the analysis of regulations and legal conditions to identify common areas, as well as advantages and disadvantages of the different systems regarding the industrial circular economy

- Analysis of aspects related to the impact of product design for circular economy to derive suitable product groups

- Analysis of applied loop strategies to identify the nature of the relationship between product, corporate strategy and loop strategy

System Structure. To close the cycle successfully, companies must be able to disassemble used parts effectively and efficiently. The costs for disassembly should be lower than the costs for purchasing a new part. Investment of companies in new lines must be kept as low as possible. Therefore, researchers must investigate whether the use of already existing assembly lines is suitable for disassembly. This way, idle times can be exploited and expensive downtimes can be avoided. In addition, the reuse of parts for remanufacturing can help to save energy and thus $\mathrm{CO}_{2}$-emissions by omitting energy-intensive material extraction and manufacturing processes. Moreover, a cheap and readily available solution for disassembly would likely increase the use of remanufacturing, thus reducing the need to produce new products.

Very few studies on the design of disassembly lines from existing assembly lines have been conducted so far. Tiwari et al. [10] argued that disassembly plays an important role in restoring and reusing the parts and components of a product as much as possible. Boothroyd et al. [11] propose a widely used approach to the design of assembly as well as disassembly lines. The objective is to reduce assembly costs and set up principles to improve product sustainability through disassembly. In the same context, Mesa et al. [12] studied open architecture products and presented metrics to assess the complexity of the various modules for assembly and disassembly. Furthermore, a lot of research focuses on disassembly, in which both deterministic and stochastic problems for complete disassembly without any target component are considered [13]. Nevertheless, there is a dearth of research when it comes to CIPSs. Compared to the assembly process, operational and physical properties are more complex in disassembly processes [14]. The most important difference is the production structure. In an assembly system, the parts converge to a single final product, whereas in a disassembly system, the parts diverge to multiple components. The first difference between assembly and disassembly line balancing is the use of various precedence graphs. Disassembly precedence constraints are often modeled 
using a transformed AND/OR graph [15]. One of the major challenges in disassembly line design is the creation of a line able to cope with the high uncertainties in inputs and outputs, especially regarding the time required for planning or configuration. Hence, these uncertainties can consist of the unknown state of the returned products. The number of returned products may vary as well as their quality and thus the type of operations to perform. While some authors tried to tackle some disassembly problems with these uncertainties (e.g. [16]), there is still unexploited potential: uncertainties have not yet been examined within the scope of integrated linear/circular lines. Mete et al. [17] published the only research paper on the topic of balancing hybrid lines for assembly and disassembly. In this work, a configuration of two parallel lines dedicated to assembly or disassembly is considered. However, the two lines can use shared workstations.

Future research is required to create a methodology that enables companies to define a suitable production system structure according to its conditions. Suitable circular material flow and the corresponding system structure must be elaborated based on qualitative aspects, i.e. the requirements definition and the assessment procedure. Furthermore, quantitative aspects must specify the derived system structure. This includes algorithms to design the circular production line at minimum costs with respect to the given throughput time. In addition, a future research direction is to investigate different possible configurations including the possibility to use the same line for assembly and disassembly or reassembly. The design of a line able to disassemble items in different conditions such as partial disassembly will also be a crucial point.

\subsection{Operating a Circular Integrated Production System}

A production system using the same resources for production and product recovery requires a proper management of resources and inventory. The integration of circular into linear systems creates challenges for operation management. On the one hand, the capacity of the line must be managed differently because the line capacity has to be divided between disassembly and assembly operations. On the other hand, the flow of re-entrant products is subject to various uncertainties in terms of the quantity and quality of items. Therefore, the development of a production planning tool to support the use of integrated assembly/disassembly lines is crucial. The resulting tool must be able to properly account for the capacity of the line, for the level of inventory of the recovered components, and for the high level of uncertainty inherent to the disassembly process.

Since the seminal work of Gupta et al. [18], the disassembly lot-sizing problems have attracted a lot of attention and Slama et al. [19] presented a recent review. Most of the literature on disassembly systems concerns the deterministic incapacitated problem [20,21], and a small number of studies focus on the stochastic capacitated version [22]. Few works exists on joint planning of reassembly and assembly. For instance, cost-optimized production planning is examined, but without considering set-up times and system dynamics [23]. Further sources for reassembly integration provide approaches for planning and control under consideration of set-up costs [24], 
in a stochastic environment [25], with the inclusion of set-up times and costs [26], for set-up and production control policies [27] and for batch size and supplier selection [28]. Finally, in practice, the product recovery process is sensitive to various sources of uncertainty, such as uncertain demand from customers, recovery rates, lead times, etc. As in supply planning for assembly systems, these uncertainties create disruptions in the disassembly plan, and lead to unmet customers' demand and difficulties with inventory management [29].

Further research is required to provide tools to help production planners to manage a factory with integrated lines. Firstly, there is currently no methodology to characterize an item and to define the suitable circular activities based on its condition. Such an approach must characterize the product's functional and geometric conditions, examine the capability of the production system with regard to product condition, and compare these characteristics to define the suitable circular activity (repair, refurbish, or disposal). Secondly, there is a need for a planning tool that extends the classical mathematical model for production planning. Such a model must both place orders to suppliers and plan the assembly and disassembly operations under limited capacity. In particular, it must account for component substitution by enabling the possibility of disassembling end-of-life items in order to substitute new components in the event of component shortage. Finally, circular activities are highly uncertain. Not only is the amount of return items unpredictable, but their quality - and thus the circular activity - varies significantly. Therefore, the approach must rely on a robust/stochastic optimization approach to integrate uncertainty in delivery lead times, returned quantity, and component quality in the model.

\subsection{Summary of the Roadmap}

The outlined state of the art as well as the derived need for research is summarized in Figure 1.

\begin{tabular}{|c|c|c|c|}
\hline & \multicolumn{2}{|c|}{ Designing an Integrated Circular Production System } & \multirow{2}{*}{$\begin{array}{l}\text { Operating an Integrated Circular } \\
\text { Production System }\end{array}$} \\
\hline & $\begin{array}{l}\text { Definition of System Boundary } \\
\text { and External Influences }\end{array}$ & System Structure & \\
\hline $\begin{array}{l}\text { State of the } \\
\text { Art }\end{array}$ & $\begin{array}{l}\text { Green logistics, treatment of } \\
\text { returns, hybrid systems with } \\
\text { separated lines }\end{array}$ & $\begin{array}{l}\text { Design of disassembly line, re- } \\
\text { configurability, remanufacturing } \\
\text { systems }\end{array}$ & $\begin{array}{l}\text { Disassembly lot-sizing problems, joint re- and } \\
\text { assembly cost optimized production planning }\end{array}$ \\
\hline $\begin{array}{l}\text { Research } \\
\text { Gap }\end{array}$ & \multicolumn{3}{|c|}{ Integration of combined lines for linear and circular production (e.g. assembly and disassembly) } \\
\hline $\begin{array}{l}\text { Field of } \\
\text { Action }\end{array}$ & $\begin{array}{l}\text { Analysis of internal and external } \\
\text { influences, definition of system } \\
\text { boundaries }\end{array}$ & $\begin{array}{l}\text { Methodology for qualitative and } \\
\text { quantitative analysis }\end{array}$ & $\begin{array}{l}\text { Production planning and scheduling } \\
\text { algorithms for integrated lines under } \\
\text { uncertainty }\end{array}$ \\
\hline $\begin{array}{l}\text { Research } \\
\text { Questions }\end{array}$ & $\begin{array}{l}\text { - What are suitable industry } \\
\text { sectors? } \\
\text { What are the regulations and } \\
\text { legal conditions? } \\
\text { What is the impact of product } \\
\text { design? } \\
\text { Which loop strategies can be } \\
\text { applied? }\end{array}$ & $\begin{array}{l}\text { - What are the requirements for } \\
\text { the production segments in } \\
\text { which lines are integrated? } \\
\text { - What is a suitable system } \\
\text { structure for integrated } \\
\text { systems? } \\
\text { - How can integrated systems be } \\
\text { configured? }\end{array}$ & $\begin{array}{l}\text { - How can the end-of-life product condition } \\
\text { be integrated in production planning? } \\
\text { - How does a mathematical model need to be } \\
\text { extended to jointly place orders with shared } \\
\text { limited capacity? } \\
\text { - How can production planning deal with } \\
\text { uncertainty in product amount and quality? }\end{array}$ \\
\hline
\end{tabular}

Fig. 1. Summarized Research Roadmap for CIPS 


\section{Conclusion}

This paper presents a vision and a road map regarding the integration of reverse flow activities within existing production systems. The innovative ideas behind the project aim to foster the adoption of circular economy by the manufacturing industry through classification of the challenges and requirements of integrated production lines. Integrating lines, especially assembly and disassembly lines, can help manufacturing companies to maintain more products at a higher value-added level. Instead of throwing away and disposing of products at the end of their life, companies can consider how they can preserve products in the best way and which of the circular processes are suitable. The possible circular processes are repairing, reusing, remanufacturing and recycling. Processes that obtain the products at the highest possible value-added level are preferable, and recycling - as material recovery should only be the last option.

We provide a description of the tools and methods required for decision-makers to design and operate integrated production lines using existing production resources for the entire cycle of manufacturing decisions including process selection, production system design, planning, scheduling, and real-time control.

\section{Acknowledgement}

This research is supported by the German-French Academy for the Industry of the Future.

\section{References}

1. Ivanov, D., 'Predicting the impacts of epidemic outbreaks on global supply chains: A simulationbased analysis on the coronavirus outbreak case', Transportation Research Part E: Logistics and Transportation Review136, (2020)

2. Queiroz, M. M., Ivanov, D., Dolgui, A. \& Wamba, S. F., 'Impacts of epidemic outbreaks on supplychains: mapping a research agenda amid the covid-19 pandemic through a structured literature review', Annals of Operations Research, (2020)

3. Prajapati, H., Kant, R., \& Shankar, R. 'Prioritizing the solutions of reverse logistics implementation to mitigate its barriers: A hybrid modified SWARA and WASPAS approach'. Journal of Cleaner Production, 240, (2019)

4. McKinnon, A., Browne, M., Whiteing, A., \& Piecyk, M. (Eds.). 'Green logistics: Improving the environmental sustainability of logistics'. Kogan Page Publ. (2015)

5. Thierry, M., Salomon, M., Van Nunen, J., \& Van Wassenhove, L. 'Strategic issues in product recovery management. California mgmt review', 37(2), (1995)

6. Lamy, Damien \& Schulz, Julia \& Zaeh, Michael. "Energy-aware scheduling in reconfigurable multiple path shop floors". Procedia CIRP. 93. 1007-1012. (2020)

7. Pintzos, G., Matsas, M., Papakostas, N., \& Mourtzis, D. "Disassembly Line Planning Through the Generation of End-of-Life Handling Information from Design Files” Procedia CIRP, 57, 740-745, (2016)

8. Rickert, J., Blömeke, S., Mennenga, M., Cerdas, F., Thiede, S., \& Herrmann, C. "Refining Circulation Factories: Classification Scheme and Supporting Product and Factory Features for Closed-Loop Production Integration.” Springer, Berlin, Heidelberg, (2020) 
9. Boutarfa, Youcef, and Ahmed Senoussi, and Nadjib Brahimi. "Reverse Logistics with Disassembly, Assembly, Repair and Substitution." IEEE International Conference on Industrial Engineering and Engineering Management, (2020)

10. Tiwari M.K., Sinha N., Kumar S., Rai R., Mukhopadhyay S.K. "A Petri net based approach to determine the disassembly strategy of a product" Int J of Prod Research 40-5, (2002)

11. Boothroyd, G., Alting, L. "Design for assembly and disassembly." CIRP 41(2), 625-636. (1992).

12. Mesa, J. A., Esparragoza, I., Maury, H. "Development of a metric to assess the complexity of assembly/disassembly tasks in open architecture products." International Journal of Production Research, 56(24), (2018)

13. Battaïa, O., Dolgui, A., Heragu, S. S., Meerkov, S. M., \& Tiwari, M. K.. Design for manufacturing and assembly/disassembly: joint design of products and production systems (2018)

14. Özceylan, Eren, Can B. Kalayci, Aşkıner Güngör, and Surendra M. Gupta. "Disassembly line balancing problem: a review of the state of the art and future directions." International Journal of Production Research 57, no. 15-16, (2019)

15. Koc, Ali, Ihsan Sabuncuoglu, and Erdal Erel. "Two exact formulations for disassembly line balancing problems with task precedence diagram construction using an AND/OR graph." In: Transactions 41, no. 10: 866-881. (2009)

16. Bentaha, Mohand Lounes, Olga Battaïa, and Alexandre Dolgui. "A sample average approximation method for disassembly line balancing problem under uncertainty." Computers \& Operations Research 51, (2014)

17. Mete, Süleyman, Zeynel Abidin Çil, Eren Özceylan, Kürşad Ağpak, and Olga Battaïa. "An optimisation support for the design of hybrid production lines including assembly and disassembly tasks." Intl Journal of Production Research 56, no. 24, (2018)

18. Gupta, S., Taleb, K., Scheduling disassembly. Int J of Production Research 32, (1994)

19. Slama, I., Ben-Ammar, O., Masmoudi, F., Dolgui, A. Disassembly scheduling problem: literature review and future research directions. IFAC-PapersOnLine 52, 601-606. (2019)

20. Godichaud, M., Amodeo, L. Eoq inventory models for disassembly systems withdisposal and lost sales. International Journal of Production Research 57, 5685-5704. (2019)

21. Kim, H. W., Park, C., \& Lee, D. H. Selective disassembly sequencing with random operation times in parallel disassembly environment. Int J of Production Research, 56(24), (2018)

22. Slama, I., Ben-Ammar,O., Thevenin, S., Dolgui, A., and Masmoudi F.. "Stochastic program for disassembly lot-sizing under given demand and uncertain component refurbishing lead times." Under review (2021)

23. Macedo, P; Alem, D; Santos, M; Junior, M; Moreno, A.: Hybrid manufacturing and remanufacturing lot-sizing problem with stochastic demand, return, and setup costs. Int J Adv Manuf Technol 82, (2016)

24. Assid, M; Gharbi, A; Hajji, A.: Production and setup control policy for unreliable hybrid manufacturing-remanufacturing systems. Journal of Manufacturing Systems 50, (2019)

25. Polotski, V; Kenne, J.-P; Gharbi, A.: Production Policy Optimization in Flexible ManufacturingRemanufacturing Systems. IFAC-PapersOnLine 49 12, (2016)

26. Polotski, V; Kenne, J.-P; Gharbi, A.: Production and setup policy optimization for hybrid manufacturing-remanufacturing systems. Int J of Production Economics 183, (2017)

27. Polotski, V; Kenne, J.-P; Gharbi, A.: Set-up and production planning in hybrid manufacturing remanufacturing systems with large returns. Intl J of Prod Research, (2017)

28. Zouadi, T; Yalaoui, A; Reghioui, M; El Kadiri, K.: Hybrid manufacturing/remanufacturing lotsizing problem with returns supplier's selection under, carbon emissions constraint. IFACPapersOnLine 49, (2016)

29. Thevenin, S., Adulyasak, Y., \& Cordeau, J. F. Material requirements planning under demand uncertainty using stochastic optimization. Production and Operations Management, 30(2), (2021) 